\title{
Robotic versus open oncological gastric surgery in the elderly: a propensity score-matched analysis
}

\author{
Giovanni Maria Garbarino ${ }^{1}$ (D) Gianluca Costa ${ }^{1}$. Barbara Frezza ${ }^{1,2} \cdot$ Alessia Biancafarina $^{2} \cdot$ Genoveffa Balducci $^{1}$. \\ Paolo Mercantini ${ }^{1} \cdot$ Marco De Prizio ${ }^{2} \cdot$ Giovanni Gugliemo Laracca ${ }^{1} \cdot$ Graziano Ceccarelli ${ }^{2,3}$
}

Received: 6 July 2020 / Accepted: 24 October 2020 / Published online: 5 November 2020

(c) The Author(s) 2020

\begin{abstract}
Although there is no agreement on a definition of elderly, commonly an age cutoff of $\geq 65$ or 75 years is used. Even if robotassisted surgery is a validated option for the elderly population, there are no specific indications for its application in the surgical treatment of gastric cancer. The aim of this study is to evaluate the safety and feasibility of robot-assisted gastrectomy and to compare the short and long-term outcomes of robot-assisted (RG) versus open gastrectomy (OG). Patients aged $\geq 70$ years old undergoing surgery for gastric cancer at the Department of Surgery of San Donato Hospital in Arezzo, between September 2012 and March 2017 were enrolled. A 1:1 propensity score matching was performed according to the following variables: age, Sex, BMI, ASA score, comorbidity, T stage and type of resection performed. 43 OG were matched to $43 \mathrm{RG}$. The mean operative time was significantly longer in the RG group ( $273.8 \mathrm{vs.} 193.5 \mathrm{~min}, p<0.01$ ). No differences were observed in terms of intraoperative blood loss, an average number of lymph nodes removed, mean hospital stay, morbidity and mortality. OG had higher rate of major complications (6.9 vs. $16.3 \%$, OR $2.592,95 \%$ CI $0.623-10.785, p=0.313$ ) and a significantly higher postoperative pain $(0.95$ vs. $1.24, p=0.042)$. Overall survival $(p=0.263)$ and disease-free survival $(p=0.474)$ were comparable between groups. Robotic-assisted surgery for oncological gastrectomy in elderly patients is safe and effective showing non-inferiority comparing to the open technique in terms of perioperative outcomes and overall 5-year survival.
\end{abstract}

Keywords Gastric cancer · Robotic surgery · Minimally Invasive Surgery · Gastric Surgery

\section{Introduction}

Gastric cancer (GC) is the fifth most common cancer and the third leading cause of cancer-related death worldwide [1].

Giovanni Maria Garbarino

giovannimaria.garbarino@uniroma1.it

Gianluca Costa

gianluca.costa@uniroma1.it

Barbara Frezza

frezzabarbara@libero.it

Alessia Biancafarina

alessia.biancafarina@uslsudest.toscana.it

Genoveffa Balducci

genoveffa.balducci@uniroma1.it

Paolo Mercantini

paolo.mercantini@uniroma1.it

Marco De Prizio

deprizio.marco@gmail.com
Population aging continues to grow with significant implications for each national health system, particularly in western countries, increasing the burden of resources for assistance $[2,3]$. With this trend, cancer will become a disease of the elderly. In this aged population, cancer often

Giovanni Gugliemo Laracca

giovanniguglielmo.laracca@uniroma1.it

Graziano Ceccarelli

g.cecca2003@libero.it

1 Department of Medical Surgical Sciences and Translational Medicine, Sapienza University of Rome, Sant'Andrea Hospital, Via di Grottarossa 1035-39, 00189 Rome, Italy

2 Division of General Surgery, Department of Surgery, San Donato Hospital, via Pietro Nenni 20-22, 52100 Arezzo, Italy

3 Division of General Surgery, Department of Surgery, San Giovanni Battista Hospital, Local Health Service Umbria 2, via Massimo Arcamone 1, 06034 Foligno, PG, Italy 
presents itself as an advanced stage of the disease. Therefore, the overall 5-year survival rate of patients with gastric cancer in western countries is around 25\% [4].

Elderly patients compared to younger ones often have one or more comorbidities and are often "fragile"; are at greater risk of morbidity and mortality. The frail elderly are less able to tolerate the stress of medical diseases, hospitalizations and immobility; as a result, surgery can be a substantial problem in this population, showing an increase of complication rates, mortality, length of hospital stay and ICU admissions [5].

In this sense, laparoscopic surgery has been shown to be better tolerated than open surgery in the selected elderly population [6].

Robot-assisted surgery allows multiple patients to benefit from minimally invasive surgery (MIS), overcoming many laparoscopic drawbacks and limitations [7]. It is used and widely accepted in general surgery and in particular in oncological surgery [8-11]. Concerning oncological gastric surgery, the robot-assisted technique has been shown to have many advantages compared to open technique, such as less blood loss, early bowel movements, faster mobilization, and shorter hospital stay [9, 12-14]. Despite that, there are no specific guidelines for its application in gastric cancer patients.

The aim of this study is to evaluate the safety and feasibility of robotic gastrectomy in the elderly comparing the short and long-term outcomes of robotic (RG) versus open gastrectomy (OG).

\section{Patients and methods}

This is a retrospective observational study concerning all consecutive patients undergoing surgery for gastric cancer at the Department of Surgery of San Donato Hospital in Arezzo between September 2012 and March 2017. Data were retrieved from a prospectively maintained database including all patients undergoing any gastric procedure for both benign and malignant condition. The research was undertaken as a part of a residency program of the Department of Medical Surgical Sciences and Translational Medicine of Sapienza University of Rome in Sant'Andrea Teaching Hospital. Data included in this study were: demographics (age, sex, ASA score, BMI, comorbidities), tumour characteristics, operative details, tumour pathology, shortterm outcomes, overall survival. The following inclusion criteria were considered: (1) patients undergoing minimally invasive or open gastrectomy for a histologically proven gastric carcinoma with pre-operative CT staging and multidisciplinary team evaluation; (2) patients $\geq 70$ years old; (3) at least D2 lymphadenectomy, and (4) procedure performed by the senior surgeon. The exclusion criteria were:
(1) patients $<70$ years old; (2) patients with tumour located at the gastro-oesophageal junction.

Patients were divided into two groups according to the surgical approach: robotic (RG group) and open (OG group).

Robotic procedures converted to open were analysed according to the intention-to-treat principle and included in the RG group.

The primary endpoint was to compare the short-term outcomes between open and robotic approach focusing on morbidity and mortality within 30 days from surgery. As secondary endpoints, long-term 5-year overall survival (OS) and disease-free survival (DFS) were evaluated and compared between groups.

All patients were discussed in a multidisciplinary environment involving surgeons, medical oncologists, radiologists and pathologists.

This study was conducted in accordance with the Declaration of Helsinki and its later amendments or comparable ethical standards. A formal Institutional Review Board approval was not required because of the non-interventional retrospective design; however, a signed consent for the treatment and the analysis of data for the scientific purpose was obtained from all patients before any surgical procedures.

\section{Definitions}

Comorbidities were categorized according to the Charlson Age Comorbidities Index (CACI).

Preoperative clinical staging was assessed in all patients by total body CT scan and endoscopic ultrasound when indicated.

Tumour staging was performed according to 7th TNM edition [15].

A 4-point Verbal Rating Scale (VRS) scale was used for the evaluation of postoperative pain: 0 point corresponds to the absence of pain, one point to some pain, two points to considerable pain and three points to a pain which could not be more severe.

Morbidity and mortality were defined as postoperative complications and death within 30 days from surgery respectively. Morbidity was graded according to the Clavien-Dindo classification and complications graded $\geq$ III were defined as major [16].

Reoperation was defined as every surgical procedure following primary surgery during hospitalization or within 30 days after a primary intervention.

Overall survival (OS) was defined as the time between surgery and death for any cause or last follow-up.

No patients underwent neoadjuvant chemotherapy and patients were treated with adjuvant chemotherapy (oxaliplatin and capecitabine) after surgery when indicated as proposed in the "Associazione Italiana di Oncologia Medica" (AIOM) guidelines at the time of the surgical treatment [17]. 


\section{Statistical analysis}

Continuous data were expressed as the mean ( \pm standard deviation) or median and interquartile range (IQR 25-75\%) depending on their distribution that was assessed through the Shapiro-Wilks test. Unpaired Student $t$ test was used to compare differences in continuous parametric variables and the Mann-Whitney $U$ test for continuous nonparametric variables. Numbers and percentages were used for reporting categorical variables and the $\chi^{2}$ test or Fisher's exact test with or without Yates correction were used for comparisons.

A propensity score matching was applied to eliminate selection bias between groups and was reported according to the recommendations of Lonjon et al. [18]. Variables influencing decision regarding surgical approach and variables with potential influence on outcomes were assigned propensity scores using a bivariate logistic regression model. The final model included the following variables: age, Sex, BMI, ASA score, comorbidity, T stage and type of resection performed. We matched propensity scores 1:1 with the use of the nearest neighbour methods without replacement by using the closest calipers width to achieve the maximum number of cases without statistical differences in confounders variables. Survival analyses were conducted using the Kaplan-Meier method with log-rank test comparisons. Significance was defined as a $p$ value less than 0.05 . Statistical analysis was performed using the SPSS software 25.0 (SPSS, Inc., Chicago, IL).

\section{Results}

Between September 2012 and March 2017, a total of 123 patients fulfilled the study criteria and were included in the analysis. Seventy-seven patients underwent an open gastrectomy while 46 patients were operated on by robotic approach.

\section{Baseline variables before matching}

No significant differences were observed between groups in terms of sex, ASA score, BMI, comorbidities, Charlson Age Comorbidities Index (CACI) and tumor histotype. (Table 1). Significantly elderly patients were operated in the open group compared to robotic $(80.6 \pm 5.8$ years vs. $77.5 \pm 4.2$ years; $p=0.003$ ). Finally, in the unmatched cohorts, more patients underwent distal gastrectomy by robotic approach $(58.4 \%$ vs. $73.9 \%, p=0.124)$; whereas the majority of total gastrectomy were performed in the open group $(27.3 \%$ vs. $19.6 \%, p=0.124)$. This results from the different tumor location: RG group accounts more distal tumors ( $42.9 \%$ vs. $67.4 \%$ ) while OG group had more proximal neoplasms ( $24.7 \%$ vs. $10.9 \%),(p=0.029)$.
Baseline variables and short-term outcomes after matching

After propensity score matching, 43 OG were compared to 43 RG. Distal gastrectomy was the most common type of operation performed in both groups $(62.8 \%$ in OG vs. $72.1 \%$ in RG; $p=0.654$ ).

The mean operative time was significantly lower in the OG: $189.3 \pm 58.7$ vs. $267.9 \pm 88.0 \min p<0.001$. Conversion during RG occurred in 6 (14\%) patients: for uncontrolled bleeding ( 2 patients), for the severe adhesive syndrome ( 1 patient) and for the infiltration of the transverse mesocolon or anterior pancreatic capsule ( 3 patients). The blood loss did not differ between the two groups: $85.0 \pm 27.6$ vs. $86.7 \pm 71.1 \mathrm{~mL}, p=0.198$. Postoperative outcomes are depicted in Table 2. Time to first flatus $(p=0.471)$ as well as time to first stool $(p=0.222)$ and time to soft oral intake $(p=0.380)$ are comparable between OG and RG. Postoperative pain was significantly lower in the RG $(1.24 \pm 0.7$ vs. $0.95 \pm 0.7, p=0.042$ ). Morbidity was similar between groups ( $p=0.662$ ) with most of the complications being minor according to Clavien-Dindo classification $(25.6 \%$ in OG vs. $30.2 \%$ in RG $p=0.198$ ). Furthermore, major complications mostly occurred after open surgery $(16.3 \%$ vs. $6.9 \%$, OR $2.592,95 \%$ CI $0.623-10.785, p=0.313$ ). In particular, in the OG group three patients underwent reoperation: one patient for cholecystitis with pancreatitis, one for intestinal occlusion by ileal volvulus and one for biliary peritonitis. One patient underwent pleural drainage for pleural effusion, one patient to endoscopic dilatation of anastomotic stenosis and the last patient with major complication suffered from an anastomotic leak conservatively treated, but developed stroke and pleural effusion (Table 2).

Concerning the RG group, two patients underwent reoperation: one for the leak of the duodenal stump and the other for a twisting of the gastro-jejunal anastomosis. The third patient with major complication underwent endoscopic dilatation of anastomotic stenosis.

Finally, length of hospital stay was comparable between groups ( 9 vs. 9 days; $p=0.685$ ).

\section{Pathological and long-term outcomes}

Pathological examination of the resected specimen showed comparable sizes of the tumor (5.8 vs $4.6 \mathrm{~cm} ; p=0.267$ ), $\mathrm{T}$ stage $(p=0.575), \mathrm{N}$ stage $(p=0.340)$ and $\mathrm{M}$ stage $(p=1.000)$ between groups (Table 3). Furthermore, overall R0 resection was achieved in $86.0 \%$ and $95.3 \%$, of cases in $\mathrm{OG}$ and RG respectively $(p=0.181)$.

Finally, the number or retrieved lymph nodes (22.5 vs $22.1, p=0.856$ ) was comparable between groups, but the open group had more metastatic lymph nodes $(7.4 \%$ vs. 
Table 1 Baseline characteristics before and after propensity score matching

\begin{tabular}{|c|c|c|c|c|c|c|}
\hline & \multicolumn{2}{|c|}{$\begin{array}{l}\text { Before propensity score } \\
\text { matching }\end{array}$} & \multirow[t]{2}{*}{$p$} & \multicolumn{2}{|c|}{$\begin{array}{l}\text { After propensity score } \\
\text { matching }\end{array}$} & \multirow[t]{2}{*}{$p$} \\
\hline & $\begin{array}{l}\text { Open } \\
n=77\end{array}$ & $\begin{array}{l}\text { Robotic } \\
n=46\end{array}$ & & $\begin{array}{l}\text { Open } \\
n=43\end{array}$ & $\begin{array}{l}\text { Robotic } \\
n=43\end{array}$ & \\
\hline Age (years, mean $\pm S D$ ) & $80.6( \pm 5.8)$ & $77.5( \pm 4.2)$ & 0.003 & $78.5( \pm 5.3)$ & $77.7( \pm 4.2)$ & 0.522 \\
\hline Gender F/M & $32 / 45$ & $25 / 21$ & 0.169 & $22 / 21$ & $23 / 20$ & 0.829 \\
\hline BMI (mean, $\pm \mathrm{SD}$ ) & $23.0( \pm 5.8)$ & $23.2( \pm 5.0)$ & 0.908 & $23.8( \pm 4.9)$ & $23.3( \pm 5.1)$ & 0.492 \\
\hline $\operatorname{ASA}(n, \%)$ & & & 0.552 & & & 0.787 \\
\hline 1 & $1(1.3 \%)$ & $0(0.0 \%)$ & & $0(0.0 \%)$ & $0(0.0 \%)$ & \\
\hline 2 & $26(33.8 \%)$ & $16(34.8 \%)$ & & $16(37.2 \%)$ & $13(30.2 \%)$ & \\
\hline 3 & $42(54.5 \%)$ & $28(60.9 \%)$ & & $25(58.1 \%)$ & $28(65.1 \%)$ & \\
\hline 4 & $8(10.4 \%)$ & $2(4.3 \%)$ & & $2(4.7 \%)$ & $2(4.7 \%)$ & \\
\hline Comorbidities $(n, \%)$ & $72(93.5 \%)$ & $40(87.0 \%)$ & 0.365 & $41(95.3 \%)$ & $40(93.0 \%)$ & 1.000 \\
\hline CACI (median, range) & $5(3-9)$ & $4(3-11)$ & 0.148 & $4(3-8)$ & $4(3-11)$ & 0.729 \\
\hline Histotype & & & 0.551 & & & 0.663 \\
\hline Intestinal & $39(50,6 \%)$ & $29(63.0 \%)$ & & $23(53.5 \%)$ & $26(60.5 \%)$ & \\
\hline Diffuse & $25(32.5 \%)$ & $11(23.9 \%)$ & & $16(37.2 \%)$ & $11(25.6 \%)$ & \\
\hline Signet-ring cell & $4(5.2 \%)$ & $2(4.3 \%)$ & & $1(2.3 \%)$ & $2(4.7 \%)$ & \\
\hline Mucinous & $9(11.7 \%)$ & $4(8.7 \%)$ & & $3(7.0 \%)$ & $4(9.3 \%)$ & \\
\hline Tumor location & & & 0.029 & & & 0.401 \\
\hline Subcardial & $12(15.6 \%)$ & $4(8.7 \%)$ & & $4(9.3 \%)$ & $4(9.3 \%)$ & \\
\hline Fundus & $7(9.1 \%)$ & $1(2.2 \%)$ & & $3(7.0 \%)$ & $1(2.3 \%)$ & \\
\hline Body & $15(19.5 \%)$ & $8(17.4 \%)$ & & $8(18.6 \%)$ & $8(18.6 \%)$ & \\
\hline Angulus & $5(6.5 \%)$ & $0(0.0 \%)$ & & $2(4.7 \%)$ & $0(0.0 \%)$ & \\
\hline Antrum & $29(37.7 \%)$ & $31(67.4 \%)$ & & $21(41.8 \%)$ & $28(65.1 \%)$ & \\
\hline Pylorus & $4(5.2 \%)$ & $0(0.0 \%)$ & & $2(4.7 \%)$ & $0(0.0 \%)$ & \\
\hline Gastric stump & $5(6.5 \%)$ & $2(4.3 \%)$ & & $3(7.0 \%)$ & $2(4.7 \%)$ & \\
\hline Tumor size $(\mathrm{cm}$, mean $\pm \mathrm{SD})$ & $6.4( \pm 4.1)$ & $4.6( \pm 2.5)$ & 0.073 & $5.8( \pm 3.8)$ & $4.6( \pm 2.5)$ & 0.267 \\
\hline
\end{tabular}

$B M I$ body mass index, ASA American Society of Anesthesiology, CACI Charlson Age-Comorbidities Index
$4.0 \%, p=0.053)$ and a higher lymph node ratio (0.3 vs. 0.2 , $p=0.043$ ).

After a median follow-up of 32.0 (16.8-47.2) months for OG and 52.0 (15.3-88.7) months for RG, the 1-3-5 years OS rate was $73.7 \%, 41.8 \%$ and $31.3 \%$ for open and $82.7 \%$, $52.3 \%$ and $34.9 \%$ for robotic ( $p=0.263$; Fig. 1$)$; whereas 1-3-5 years DFS rate was $62.6 \%, 42.4 \%$ and $42.4 \%$ for open and $65.1 \%, 51.6 \%$ and $51.6 \%(p=0.474$; Fig. 2$)$.

\section{Discussion}

The elderly population is steeply increasing worldwide but there is no agreement on a definition of elderly. Many studies define as "elderly" only patients older than 75 years $[19,20]$. Nowadays, the WHO still considers as elderly those individuals of 60 years or over; however, most scientific societies define patients as elderly if their age is 65 year or more.

Elderly patients have an increased operative risk and high postoperative morbidity and mortality rate because of associated diseases such as hepatic, cardiovascular, and pulmonary diseases [21]. Thus, elderly patients are often unable to bear neoadjuvant or adjuvant chemotherapy [22].

Despite that, nowadays it is not justified to deny surgical procedures to elderly patients based only on age. Elderly patients who survive the first year after surgery have been shown to have the same cancer-related survival as younger patients [23].

However, as major abdominal surgery in elderly and frail patients is related to a higher risk of morbidity and mortality, they can benefit from an integrated, team-based approach. This should include geriatricians, anesthesiologists, oncologists and surgeons working together to optimize drug management eventually reducing general morbidity and acute geriatric events as well as other complications and the total length of hospitalization [24, 25].

The advantages of minimally invasive surgery (MIS) characterized by small incisions has provided many benefits over open surgery including less intraoperative blood loss, faster postoperative bowel function, shorter hospital stay, less postoperative pain, fewer wound infections, and a lower incidence of postoperative pneumonia and incidence 
Table 2 Operative and postoperative outcomes before and after propensity score matching

\begin{tabular}{|c|c|c|c|c|c|c|}
\hline & \multicolumn{2}{|c|}{ Before propensity score matching } & \multirow[t]{2}{*}{$p$} & \multicolumn{2}{|c|}{ After propensity score matching } & \multirow[t]{2}{*}{$p$} \\
\hline & $\begin{array}{l}\text { Open } \\
n=77\end{array}$ & $\begin{array}{l}\text { Robotics } \\
n=46\end{array}$ & & $\begin{array}{l}\text { Open } \\
n=43\end{array}$ & $\begin{array}{l}\text { Robotics } \\
n=43\end{array}$ & \\
\hline Type of gastrectomy $(n, \%)$ & & & 0.124 & & & 0.654 \\
\hline Distal & $45(58.4 \%)$ & $34(73.9 \%)$ & & $27(62.8 \%)$ & $31(72.1 \%)$ & \\
\hline Total & $21(27.3 \%)$ & $9(19.6 \%)$ & & $12(27.9 \%)$ & $9(20.9 \%)$ & \\
\hline Degastro-gastrectomy & $7(9.1 \%)$ & $3(6.5 \%)$ & & $4(9.3 \%)$ & $3(7.0 \%)$ & \\
\hline Proximal & $4(5.2 \%)$ & $0(0.0 \%)$ & & $0(0.0 \%)$ & $0(0.0 \%)$ & \\
\hline Operative Time (min, mean \pm SD) & $188.2( \pm 66.5)$ & $267.4( \pm 83.3)$ & $<0.001$ & $189.3( \pm 58.7)$ & $267.9( \pm 88.0)$ & $<0.001$ \\
\hline Conversion $(n, \%)$ & & $8(17.4 \%)$ & & & $6(14 \%)$ & \\
\hline Blood loss $($ mean \pm SD) & $83.8( \pm 29.3)$ & $85.9( \pm 68.7)$ & 0.268 & $85.0( \pm 27.6)$ & $86.7( \pm 71.1)$ & 0.198 \\
\hline Pain after $6 \mathrm{~h}(\mathrm{VRS}$, mean $\pm \mathrm{SD})$ & $1.29( \pm 0.9)$ & $0.93( \pm 0.8)$ & 0.029 & $1.24( \pm 0.7)$ & $0.95( \pm 0.7)$ & 0.042 \\
\hline Time to first flatus (days, mean \pm SD) & $4.3( \pm 1.2)$ & $4.4( \pm 0.9)$ & 1.000 & $4.5( \pm 1.2)$ & $4.4( \pm 0.9)$ & 0.471 \\
\hline Time to first stool (days, mean \pm SD) & $5.8( \pm 2.0)$ & $5.5( \pm 0.9)$ & 0.403 & $6.0( \pm 2.3)$ & $5.5( \pm 0.9)$ & 0.222 \\
\hline Time to oral intake (days, mean \pm SD) & $4.9( \pm 1.8)$ & $4.9( \pm 0.8)$ & 0.223 & $5.0( \pm 2.0)$ & $4.9( \pm 0.8)$ & 0.380 \\
\hline Hospital stay (days, median) & $9(6-27)$ & $9(7-90)$ & 0.454 & $9(6-25)$ & $9(7-90)$ & 0.685 \\
\hline 30 days morbidity (Clavien-Dindo I-IV) $(n, \%)$ & $30 / 77(39.0 \%)$ & $18 / 46(39.1 \%)$ & 1.000 & $18 / 43(41.9 \%)$ & $16 / 43(37.2 \%)$ & 0.662 \\
\hline Clavien-Dindo I-II & $20 / 77(25.9 \%)$ & $15 / 46(32.6 \%)$ & 0.431 & $11 / 43(25.6 \%)$ & $13 / 43(30.2 \%)$ & 0.806 \\
\hline Clavien-Dindo III-IV & $10 / 77(12.9 \%)$ & $3 / 46(6.5 \%)$ & 0.367 & $7 / 43(16.3 \%)$ & $3 / 43(6.9 \%)$ & 0.313 \\
\hline Re-operation $(n, \%)$ & $8 / 77(10.4 \%)$ & $2 / 46(4.3 \%)$ & 0.318 & $5 / 43(11.6 \%)$ & $2 / 43(4.7 \%)$ & 0.433 \\
\hline 30 days mortality $(n, \%)$ & $4 / 77(5.2 \%)$ & $0 / 46(0.0 \%)$ & 0.296 & $1 / 43(2.3 \%)$ & $0 / 43(0.0 \%)$ & 1.000 \\
\hline
\end{tabular}

VRS Verbal Rating Scale

of postoperative heart complications. All those benefits were widely demonstrated in the Eastern multicentric randomized control trials of high-volume centers for both early and locally advanced gastric cancer; for that reason, we recently investigated our results about locally advanced gastric cancer in middle-low volume centers in a western setting [26-28].

Robotic surgery must be considered as the natural evolution of conventional MIS laparoscopy, consisting of a computerized interface to facilitate intuitive movements (EndoWristTM System) similar to conventional open surgery.

Focusing on gastric surgery, the introduction of roboticassisted technique in the early 2000 s allowed to overcome some technical limitations of laparoscopy, especially during the reconstructive time and the execution of D2 lymphadenectomy [7-9]. Robotic technology enables accurate dissection of lymphocellular tissue, reducing the risk of bleeding. The advantages are particularly evident when the lymph node dissection must be conducted circumferentially around the vessels $[29,30]$. In fact, in some series the average number of lymph nodes removed with the robotic technique was superior to laparoscopy $[13,31]$.

Since that time, several studies have demonstrated the safety and efficacy of robot-assisted gastrectomy in the treatment of gastric adenocarcinoma [10, 32, 33].

At present, there is no evidence that robotic surgery should be considered better than minimally invasive conventional surgery, even because overall operating times and costs are still higher than laparoscopy [9, 12, 31].

On the other hand, robotic surgery increases MIS access to patients by reducing the overall conversion rate and learning curve compared to conventional laparoscopy [34, 35]. Furthermore, the dual console platform allows a step by step teaching in the setting of a residency program on robotic surgery.

The present study, focusing on the safety and feasibility of robotic gastric surgery, highlights that this surgical approach could lead to possible benefits in the elderly population.

Indeed, the reduced odds ratio of major postoperative complications associated with a significant lower postoperative pain seems to be an important advantage for such a frail cohort of patients.

In fact, it is well known that the reduction in postoperative pain is very important for the patient and for their total experience of the surgical procedure. More important still is the association between postoperative pain and immune deficiency, wound healing and the occurrence of chronic pain $[36,37]$. The reduction of postoperative pain experienced by the patient improves mobilisation and ultimately reduces adverse postoperative outcome [38].

Moreover, the reduced consumption of analgesics could lead to a lower risk of pharmacological interactions in patients with severe comorbidities and multidrug therapies. 
Table 3 Oncological outcomes

\begin{tabular}{|c|c|c|c|}
\hline & $\begin{array}{l}\text { Open } \\
n=43\end{array}$ & $\begin{array}{l}\text { Robotic } \\
n=43\end{array}$ & $p$ \\
\hline T-stage $(n, \%)$ & & & 0.575 \\
\hline pT1 & $5(11.6 \%)$ & $11(25.6 \%)$ & \\
\hline pT2 & $7(16.3 \%)$ & $7(16.3 \%)$ & \\
\hline pT3 & $13(30.2 \%)$ & $13(30.2 \%)$ & \\
\hline pT4 & $18(41.8 \%)$ & $12(27.9 \%)$ & \\
\hline N-stage $(n, \%)$ & & & 0.340 \\
\hline pNO & $14(32.6 \%)$ & $23(53.5 \%)$ & \\
\hline $\mathrm{pN} 1$ & $7(16.3 \%)$ & $5(11.6 \%)$ & \\
\hline $\mathrm{pN} 2$ & $6(14.0 \%)$ & $6(14.0 \%)$ & \\
\hline pN3 & $16(37.2 \%)$ & $9(20.9 \%)$ & \\
\hline M-stage $(n, \%)$ & & & 1.000 \\
\hline $\mathrm{pM} 0$ & $38(88.4 \%)$ & $38(88.4 \%)$ & \\
\hline pM1 & $5(11.6 \%)$ & $5(11.6 \%)$ & \\
\hline $\mathrm{R} 0$ resection $(n, \%)$ & $37(86.0 \%)$ & $41(95.3 \%)$ & 0.181 \\
\hline Retrieved nodes (mean \pm SD) & $22.5( \pm 12.8)$ & $22.1( \pm 8.4)$ & 0.856 \\
\hline Positive nodes $($ mean \pm SD) & $7.4( \pm 11.1)$ & $4.0( \pm 6.9)$ & 0.053 \\
\hline Node ratio $($ mean $\pm S D)$ & $0.3( \pm 0.3)$ & $0.2( \pm 0.3)$ & 0.043 \\
\hline TNM stage $(n, \%)$ & & & 0.627 \\
\hline IA & $4(9.3 \%)$ & $8(18.6 \%)$ & \\
\hline IB & $3(7.0 \%)$ & $7(15.2 \%)$ & \\
\hline IIA & $9(20.9 \%)$ & $8(18.6 \%)$ & \\
\hline IIB & $4(9.3 \%)$ & $4(9.3 \%)$ & \\
\hline IIIA & $5(11.6 \%)$ & $3(7.0 \%)$ & \\
\hline IIIB & $3(7.0 \%)$ & $4(9.3 \%)$ & \\
\hline IIIC & $10(23.3 \%)$ & $4(9.3 \%)$ & \\
\hline IV & $5(11.6 \%)$ & $5(11.6 \%)$ & \\
\hline
\end{tabular}

Unlike what has been reported, no differences were found in the current series between the two groups regarding the hospital stay. This finding is not surprising when Enhanced Recovery After Surgery (ERAS) Protocols are not applied. In fact, the postoperative protocol was the same for all patients, regardless of the surgical approach.

Concerning the oncological safety of the robotic technique, in the current series all patients underwent a D2 lymphadenectomy with preservation of the pancreas and spleen. The average number of lymph nodes removed was above the minimum recommended by Japanese and Western guidelines $[39,40]$.

Finally, regarding the long-term results, the majority of the literature compared robot-assisted surgery and laparoscopy, without differences in terms of disease-free and overall survival [41-43]. In our series, as shown by other studies comparing robotic and open gastrectomy, no significant differences were observed in terms of OS and DFS between the two surgical approaches [44]. Probably the better survival curves of the RG group were mainly due to the higher amount of metastatic lymph nodes in the OG group.

The results of an ongoing multicentric observational trial comparing robotic, laparoscopic and open surgery for gastric cancer (IMIGASTRIC) will add some evidence to the current debate [45].

The most important limitations of the present study are the retrospective fashion of the study and the sample size. As stated above, the incidence of gastric cancer in western countries is limited; thus, it is the reason for our sample size. However, it is important to consider that the propensity score model allowed us to compare two similar groups.
Fig. 1 Patient's Overall Survival According to Surgical Approach

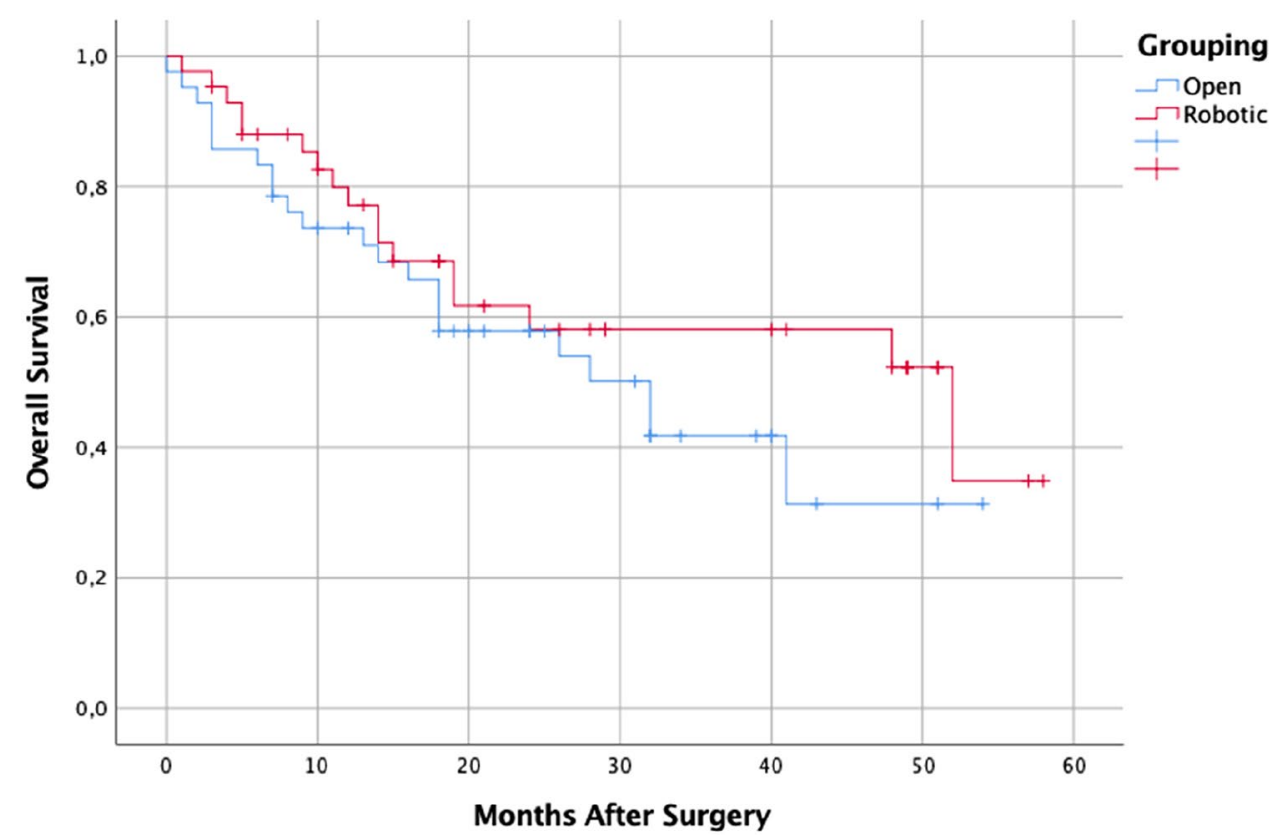


Fig. 2 Patient's Disease Free Survival According to Surgical Approach

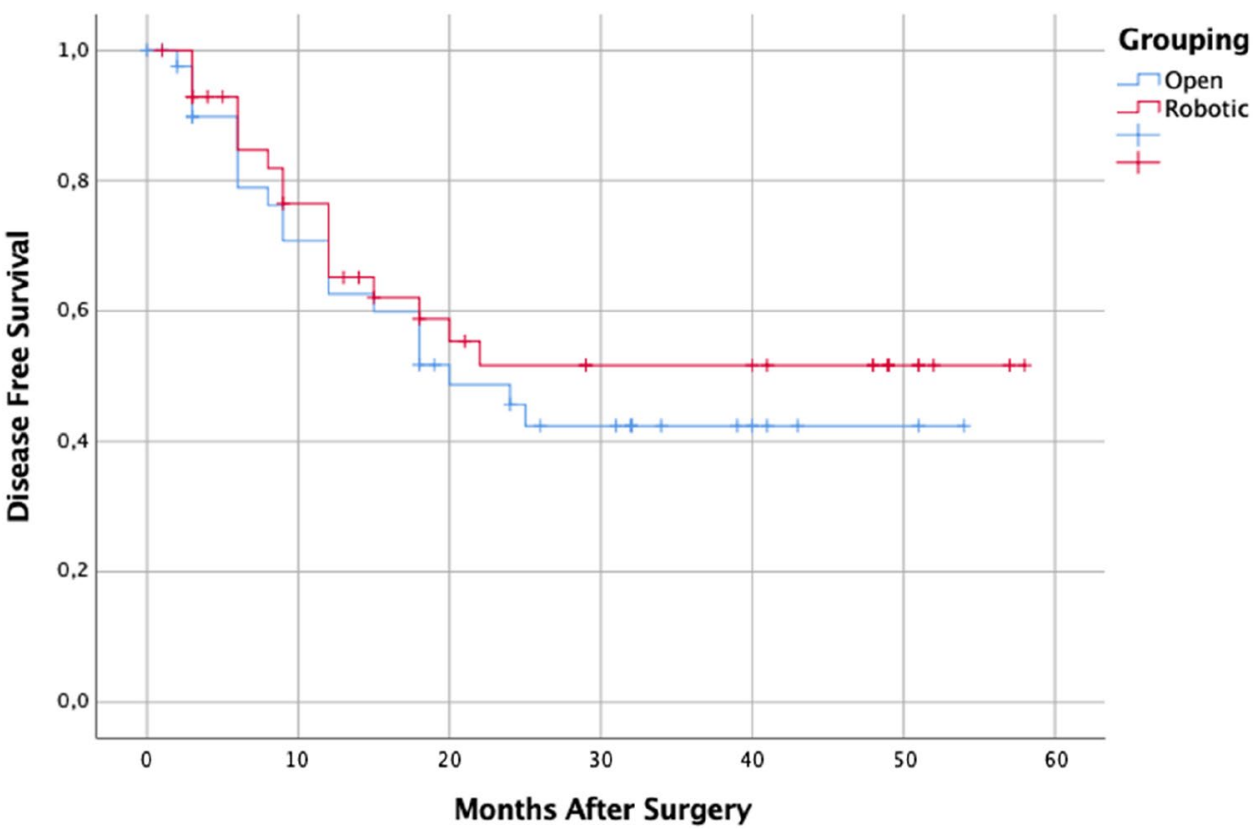

In conclusion, this study confirms that robotic surgery for gastric cancer is safe and feasible, showing similar short and long-term outcomes compared to the open technique. Despite the higher operative time and costs, robotic technology appears promising in reducing the postoperative pain and the rate of major complications. The duration of surgery and pneumoperitoneum seems to not have a negative effect on elderly patients which might benefit from a probably reduced rate of postoperative incisional hernia.

Author contributions CG study conception and design, statistical analysis and critical revision of the manuscript. GGM and LGG drafting the manuscript, statistical analysis and interpretation of the data. MP and BG conception and design of the university residency program and critical revision of the manuscript. FB and BA, residency program participants and acquisition of data., CG and PM, critical revision of the manuscript. All Authors have contributed and approved this paper.

Funding Open access funding provided by Università degli Studi di Roma La Sapienza within the CRUI-CARE Agreement.

\section{Compliance with ethical standards}

Conflict of interest The authors declare that there is no conflict of interest.

Open Access This article is licensed under a Creative Commons Attribution 4.0 International License, which permits use, sharing, adaptation, distribution and reproduction in any medium or format, as long as you give appropriate credit to the original author(s) and the source, provide a link to the Creative Commons licence, and indicate if changes were made. The images or other third party material in this article are included in the article's Creative Commons licence, unless indicated otherwise in a credit line to the material. If material is not included in the article's Creative Commons licence and your intended use is not permitted by statutory regulation or exceeds the permitted use, you will need to obtain permission directly from the copyright holder. To view a copy of this licence, visit http://creativecommons.org/licenses/by/4.0/.

\section{References}

1. Bray F, Ferlay J, Soerjomataram I, Siegel RL, Torre LA, Jemal A (2018) Global cancer statistics 2018: GLOBOCAN estimates of incidence and mortality worldwide for 36 cancers in 185 countries. CA Cancer J Clin 68:394-424

2. Yee KWL, Pater JL, Pho L, Zee B, Siu LL (2003) Enrollment of older patients in cancer treatment trials in Canada: why is age a barrier? J Clin Oncol 21:1618-1623

3. Smith BD, Smith GL, Hurria A, Hortobagyi GN, Buchholz TA (2009) Future of cancer incidence in the United States: burdens upon an aging, changing nation. J Clin Oncol 27:2758-2765

4. Ferlay J, Steliarova-Foucher E, Lortet-Tieulent J, Rosso S, Coebergh JWW, Comber $\mathrm{H}$ et al (2013) Cancer incidence and mortality patterns in Europe: estimates for 40 countries in 2012. Eur J Cancer 49:1374-1403

5. Korc-Grodzicki B, Downey RJ, Shahrokni A, Peter Kingham T, Patel SG, Audisio RA (2014) Surgical considerations in older adults with cancer. J Clin Oncol. https://doi.org/10.1200/ jco.2014.55.0962

6. Lopez CB, Cid JA, Poves I, Bettenica C, Villegas L et al (2003) Laparoscopic surgery in the elderly patient. Surg Endosc. https:// doi.org/10.1007/s00464-002-9056-7

7. Giulianotti PC (2003) Robotics in general surgery. Arch Surg. https://doi.org/10.1001/archsurg.138.7.777

8. Patriti A, Ceccarelli G, Ceribelli C, Bartoli A, Spaziani A, Cisano C et al (2011) Robot-assisted laparoscopic management of cardia carcinoma according to Siewert recommendations. Int J Med Robot 7:170-177

9. Caruso S, Patriti A, Roviello F, De Franco L, Franceschini F, Coratti A et al (2016) Laparoscopic and robot-assisted 
gastrectomy for gastric cancer: current considerations. World J Gastroenterol 22:5694-5717

10. Caruso S, Patriti A, Marrelli D, Ceccarelli G, Ceribelli C, Roviello F et al (2011) Open vs robot-assisted laparoscopic gastric resection with D2 lymph node dissection for adenocarcinoma: a casecontrol study. Int J Med Robot 7:452-458

11. Costantino CL, Mullen JT (2019) Minimally invasive gastric cancer surgery. Surg Oncol Clin N Am 28:201-213

12. Marano A, Choi YY, Hyung WJ, Kim YM, Kim J, Noh SH (2013) Robotic versus laparoscopic versus open gastrectomy: a metaanalysis. J Gastric Cancer 13:136-148

13. Liao G, Chen J, Ren C, Li R, Du S, Xie G et al (2013) Robotic versus open gastrectomy for gastric cancer: a meta-analysis. PLoS ONE 8:e81946

14. Kostakis ID, Alexandrou A, Armeni E, Damaskos C, Kouraklis G, Diamantis T et al (2017) Comparison between minimally invasive and open gastrectomy for gastric cancer in europe: a systematic review and meta-analysis. Scand J Surg 106:3-20

15. Sobin LH, Gospodarowicz MK, Wittekind C (2011) TNM classification of malignant tumours. John Wiley and Sons, New Jersey

16. Clavien PA, Barkun J, de Oliveira ML, Vauthey JN, Dindo D, Schulick RD et al (2009) The Clavien-Dindo classification of surgical complications: five-year experience. Ann Surg 250:187-196

17. Italian Association of Medical Oncology (AIOM) (2012). http:// media.aiom.it/userfiles/files/doc/LG/2012_LG_AIOM_Stoma co.pdf

18. Lonjon G, Porcher R, Ergina P, Fouet M, Boutron I (2017) Potential pitfalls of reporting and bias in observational studies with propensity score analysis assessing a surgical procedure: a methodological systematic review. Ann Surg 265:901-909

19. Fontani A, Martellucci J, Civitelli S, Tanzini G (2011) Outcome of surgical treatment of colorectal cancer in the elderly. Updates Surg 63:233-237

20. Vironen JH, Sainio P, Husa AI, Kellokumpu IH (2004) Complications and survival after surgery for rectal cancer in patients younger than and aged 75 years or older. Dis Colon Rectum. https ://doi.org/10.1007/s10350-004-0557-4

21. Ceccarelli G, Andolfi E, Biancafarina A, Rocca A, Amato M, Milone $\mathrm{M}$ et al (2017) Robot-assisted surgery in elderly and very elderly population: our experience in oncologic and general surgery with literature review. Aging Clin Exp Res 29:55-63

22. Puts MTE, Hardt J, Monette J, Girre V, Springall E, Alibhai SMH (2012) Use of geriatric assessment for older adults in the oncology setting: a systematic review. J Natl Cancer Inst 104:1133-1163

23. Dekker JWT, van den Broek CBM, Bastiaannet E, van de Geest LGM, Tollenaar RAEM, Liefers GJ (2011) Importance of the first postoperative year in the prognosis of elderly colorectal cancer patients. Ann Surg Oncol 18:1533-1539

24. Chow WB, Rosenthal RA, Merkow RP, Ko CY, Esnaola NF (2012) Optimal preoperative assessment of the geriatric surgical patient: a best practices guideline from the American College of Surgeons National Surgical Quality Improvement Program and the American Geriatrics Society. J Am Coll Surg. https://doi. org/10.1016/j.jamcollsurg.2012.06.017

25. Bell RH Jr, Drach GW, Rosenthal RA (2011) Proposed competencies in geriatric patient care for use in assessment for initial and continued board certification of surgical specialists. J Am Coll Surg 213:683-690

26. Kim W, Kim H-H, Han S-U, Kim M-C, Hyung WJ, Ryu SW et al (2016) Decreased morbidity of laparoscopic distal gastrectomy compared with open distal gastrectomy for stage I gastric cancer: short-term outcomes from a multicenter randomized controlled trial (KLASS-01). Ann Surg 263:28-35
27. Lee H-J, Hyung WJ, Yang H-K, Han SU, Park Y-K, An JY et al (2019) Short-term outcomes of a multicenter randomized controlled trial comparing laparoscopic distal gastrectomy with D2 lymphadenectomy to open distal gastrectomy for locally advanced gastric cancer (KLASS-02-RCT). Ann Surg 270:983-991

28. Garbarino GM, Costa G, Laracca GG, Castagnola G, Mercantini P, Di Paola M et al (2020) Laparoscopic versus open distal gastrectomy for locally advanced gastric cancer in middle-lowvolume centers in Western countries: a propensity score matching analysis. Langenbecks Arch Surg 405:797-807

29. Son T, Lee JH, Kim YM, Kim H-I, Noh SH, Hyung WJ (2014) Robotic spleen-preserving total gastrectomy for gastric cancer: comparison with conventional laparoscopic procedure. Surg Endosc 28:2606-2615

30. Kim Y-W, Reim D, Park JY, Eom BW, Kook M-C, Ryu KW et al (2016) Role of robot-assisted distal gastrectomy compared to laparoscopy-assisted distal gastrectomy in suprapancreatic nodal dissection for gastric cancer. Surg Endosc 30:1547-1552

31. Zong L, Seto Y, Aikou S, Takahashi T (2014) Efficacy evaluation of subtotal and total gastrectomies in robotic surgery for gastric cancer compared with that in open and laparoscopic resections: a meta-analysis. PLoS ONE. https://doi.org/10.1371/journ al.pone. 0103312

32. Kim YM, Baek S-E, Lim JS, Hyung WJ (2013) Clinical application of image-enhanced minimally invasive robotic surgery for gastric cancer: a prospective observational study. J Gastrointest Surg 17:304-312

33. Hyun M-H, Lee C-H, Kwon Y-J, Cho S-I, Jang Y-J, Kim D-H et al (2013) Robot versus laparoscopic gastrectomy for cancer by an experienced surgeon: comparisons of surgery, complications, and surgical stress. Ann Surg Oncol. https://doi.org/10.1245/s1043 4-012-2679-6

34. Zhang X, Tanigawa N (2009) Learning curve of laparoscopic surgery for gastric cancer, a laparoscopic distal gastrectomy-based analysis. Surg Endosc 23:1259-1264

35. Kim MS, Kim WJ, Hyung WJ, Kim H-I, Han S-U, Kim Y-W et al (2019) Comprehensive learning curve of robotic surgery: discovery from a multicenter prospective trial of robotic gastrectomy. Ann Surg. https://doi.org/10.1097/SLA.0000000000003583

36. Mwaka G, Thikra S, Mungayi V (2013) The prevalence of postoperative pain in the first 48 hours following day surgery at a tertiary hospital in Nairobi. Afr Health Sci. https://doi.org/10.4314/ahs. v13i3.36

37. Motamed C, Salazar G, Bourgain J-L (2010) Incidence of severe postoperative pain after cancer surgery despite intraoperative anticipation: a case controlled study. Bull Cancer 97:E37-41

38. Kehlet H, Wilmore DW (2002) Multimodal strategies to improve surgical outcome. Am J Surg. https://doi.org/10.1016/s0002 $-9610(02) 00866-8$

39. Japanese Gastric Cancer Association (2017) Japanese gastric cancer treatment guidelines 2014 (ver. 4). Gastric Cancer 20:1-19

40. Smyth EC, Verheij M, Allum W, Cunningham D, Cervantes A, Arnold D et al (2016) Gastric cancer: ESMO Clinical Practice Guidelines for diagnosis, treatment and follow-up. Ann Oncol 27:v38-v49

41. Nakauchi M, Suda K, Susumu S, Kadoya S, Inaba K, Ishida Y et al (2016) Comparison of the long-term outcomes of robotic radical gastrectomy for gastric cancer and conventional laparoscopic approach: a single institutional retrospective cohort study. Surg Endosc 30:5444-5452

42. Liao G, Zhao Z, Khan M, Yuan Y, Li X (2019) Comparative analysis of robotic gastrectomy and laparoscopic gastrectomy for gastric cancer in terms of their long-term oncological outcomes: a 
meta-analysis of 3410 gastric cancer patients. World J Surg Oncol 17:86

43. Obama K, Kim Y-M, Kang DR, Son T, Kim H-I, Noh SH et al (2018) Long-term oncologic outcomes of robotic gastrectomy for gastric cancer compared with laparoscopic gastrectomy. Gastric Cancer 21:285-295

44. Solaini L, Bazzocchi F, Pellegrini S, Avanzolini A, Perenze B, Curti R et al (2019) Robotic vs open gastrectomy for gastric cancer: a propensity score-matched analysis on short- and long-term outcomes. Int J Med Robot 15:e2019

45. Desiderio J, Jiang Z-W, Nguyen NT, Zhang S, Reim D, Alimoglu O et al (2015) Robotic, laparoscopic and open surgery for gastric cancer compared on surgical, clinical and oncological outcomes: a multi-institutional chart review. A study protocol of the International study group on Minimally Invasive surgery for gastric cancer-imigastric. BMJ Open 5:008198

Publisher's Note Springer Nature remains neutral with regard to jurisdictional claims in published maps and institutional affiliations. 